\title{
Exploring Knowledge Sharing in a Professional Network: A Central Eurasian Case
}

\author{
David L. FORD ${ }^{*}$, Laurie L. ZIEGLER ${ }^{* *}$, Ray FANG ${ }^{* * *}$, Oscar HOLMES IV ${ }^{* * *}$
}

Received: November 30, $2017 \quad$ Revised: April 20, $2018 \quad$ Accepted: April 27, 2018.

\begin{abstract}
Increasingly, managers of global teams are faced with the challenge of how to foster knowledge sharing within a virtual or hybrid community. In this study, we replicate Chiu, Hsu, \& Wang's (2006) study of the influence of social capital factors on knowledge sharing in virtual communities and extend it to reveal how both the quantity and quality of knowledge sharing may mediate between social capital factors and network involvement and commitment. The context of our investigation is a professional hybrid community in Central Eurasia. Using singleindicator structural equation modeling (SEM) to test our proposed model, we were able to demonstrate both convergent and discriminant validity among the study variables. Our study also provides partial support for the proposed model. Implications for research and practice are discussed.
\end{abstract}

Keywords: knowledge sharing, social capital, virtual communities, hybrid networks, Central Eurasia

JEL Codes Classification: D85, D91, L14

UDC: 331.1

DOI: https://doi.org/10.17015/ejbe.2018.021.01

\footnotetext{
* Corresponding Author. Naveen Jindal School of Management, University of Texas at Dallas, USA. Email:mzad@utdallas.edu

** Naveen Jindal School of Management, University of Texas at Dallas, USA. E-mail: ziegler@utdallas.edu

${ }^{* * *}$ Rotman School of Management, University of Toronto, Canada.

E-mail: ray.fang14@rotman.utoronto.ca

${ }^{* * * *}$ Camden School of Business, Rutgers University, USA. E-mail: Oscar.HolmesIV@rutgers.edu
} 


\section{Introduction}

In the last few decades, scholars have argued that today's increasingly interconnected world is moving towards a knowledge economy - an economy which relies more on intellectual capabilities than on physical inputs or natural resources (Powell \& Snellman, 2004). Companies regard knowledge as a key resource and competitive advantage (Grant, 1996; Spender, 1996). An organization can acquire knowledge in several ways. For example, companies may rely on staffing new employees or training existing ones (Brown \& Duguid, 1991). However, solely focusing on these methods is insufficient to sustain a competitive advantage (1991). Companies must also consider how to effectively exploit existing knowledge-based resources by transferring knowledge from one employee to another (Damodaran \& Olphert, 2000; Davenport \& Prusak, 1998). At the individual level, an employee's access to job-related knowledge and information is a vital determinant of his or her success (Seibert, Kraimer \& Liden, 2001). Employees can obtain knowledge through formal or informal methods. In fact, research suggests that informal relationships with coworkers may provide more efficient information sharing than formal ones (Cross \& Prusak, 2002; Morrison, 1993). Thus, understanding how knowledge flows through individuals is crucial to improving organizational effectiveness.

Knowledge sharing involves transferring explicit knowledge (e.g. formulas, processes) and tacit knowledge (e.g. experiences, know-how) between employees to solve problems, develop new ideas, or implement new projects (Cummings, 2004; Nonaka \& Takeuchi, 1995; Wang, Noe, \& Wang, 2014). Knowledge sharing can occur through e-mail, face-to-face communication, or through knowledge management systems (Cummings, 2004; McFadyen \& Cannella, 2004). Although previous research has identified several key antecedents to knowledge sharing such as trust, management support, and organizational values (Connelly \& Kelloway, 2003; Kankanhalli, Tan \& Wei, 2005; Michailova \& Minbaeva, 2012), much remains to be explored. Indeed, Ma, Huang, Wu, Dong, and Qi (2014) noted that knowledge sharing frameworks largely have their origins in Western cultures and that their application in different cultural contexts needs to be examined. Using a recently-formed regional network of corporate, civic, and nonprofit leaders in Central Eurasia as the basis for the research, this paper discusses a study that was designed to address an important question that has been understudied in past research. That is, this study addresses the research question, "what is the influence of social capital factors on the quantity and quality of knowledge sharing among network members?"

Social capital factors influence knowledge sharing. Following Nahapiet and Ghoshal's (1998) idea that social capital is divided into three dimensions (structural, relational, and cognitive), Chiu, Hsu, and Wang (2006) discovered that these dimensions provide mixed findings when predicting knowledge sharing in virtual communities. For example, their study showed that social interaction ties, 
reciprocity, and identification increased individuals' knowledge sharing quantity but not knowledge quality. In addition, and contrary to their predictions, trust (relational) and shared language (cognitive) did not have a significant impact on the quantity of knowledge sharing. The present study partially replicates and extends The Chiu et al. (2006) study by examining (1) the impact of social capital factors on the quantity and quality of knowledge sharing (replication), and (2) how knowledge quantity and knowledge quality impact the outcomes of network involvement and network commitment (direct effect) as well as serve as a bridge between social capital factors and organizationally-valued outcomes (mediating relationship). These latter relationships reflect an extension of the Chiu et al. (2006) study.

Furthermore, the present study examines these relationships within a "hybrid" virtual professional community, as opposed to a totally virtual community, in order to determine whether these relationships are relevant for such a hybrid community. We consider the subject network a hybrid community because network development and maintenance activities involve the opportunity for faceto-face contact via several educational events. Between such events, network members communicate virtually via email, social media, or telephonically.

Through exploring the research question examined in this paper, we make three main contributions to the literature. First, our findings provide additional empirical evidence to the knowledge sharing literature which has previously found mixed results (contrary to many traditional theories). Second, previous research uses social capital and network theories to explain knowledge sharing, but many of these studies rely on Nahapiet and Goshal's (1998) social capital framework without considering the closeness of distinct network ties (Wang \& Noe, 2010). Our research addresses this issue by considering the closeness of the advice, friendship, and network ties of study participants. Third, while previous studies have mainly focused on personal attributes and social network attributes (Chiu, Hsu, \& Wang, 2006), we analyze the mediating effect of knowledge sharing quantity and quality on the relationship between social capital attributes and personal network outcomes of involvement and commitment.

\section{Theoretical Background}

\subsection{Social Cognitive Theory}

Drawing from a previous study by Chiu, Hsu, and Wang (2006), we use Social Cognitive Theory and the Social Capital Theory as the theoretical bases for the present study. Social Cognitive Theory is a learning theory based on the idea that people learn by observing others (Bandura, 1997). While the environment in which one grows up contributes to behavior, personal cognition is very important. The combination of personal factors, behavior and social network experiences all influence human behavior. In both work and non-work settings, people are not simply seeking knowledge or handling day-to-day job responsibilities. Many persons seek a sense of belongingness, friendship, and social support (Chiu, Hsu, \& 
Wang, 2006). Put simply, people desire to associate with other people with whom they have positive relationships.

Social Cognitive Theory argues that a person's behavior is partially shaped by the influences of their social network (e.g. relationships) and her or his personal cognition (e.g. system of meaning) (Bandura, 1989). Outcome expectations and self-efficacy largely guide behavior. Self-efficacy is "a judgment of one's ability to organize and execute given types of performances," whereas an outcome expectation is a "judgment of the likely consequence such performances will produce" (Bandura, 1997, p. 21). A lack of incentives (i.e. poor outcome expectations) has been found to be a barrier to knowledge sharing across cultures (Yao, Kam, \& Chan, 2007). This suggests that in the absence of positive outcomes, individuals may tend to steer away from sharing knowledge. For example, work rewards such as promotions, bonuses, and salary increases are positively related to how frequently employees make contributions to knowledge management systems (Kankanhalli, Tan, \& Wei, 2005) which, in turn, could influence employees' work involvement and work commitment. However, studies focused on extrinsic rewards have found mixed results. For example, anticipated extrinsic rewards can sometimes have a negative effect on attitudes towards knowledge sharing (Bock \& Kim 2002; Bock, Zmud, Kim, \& Lee, 2005) or no effect at all (Kwok \& Gao, 2005). Thus, research suggests that solely using Social Cognitive Theory to explain knowledge sharing is insufficient. Moreover, the Social Cognitive Theory "is silent concerning what resources are embedded within a social network and how they affect an individual's behavior" (Chiu, Hsu, \& Wang, 2006, pg. 1875). Therefore, we also draw on Social Capital Theory to help explain knowledge sharing as discussed in the following section.

\subsection{Social Capital Theory}

Social Capital Theory posits that social networks, the relationships possessed by an individual, strongly influence the extent to which interpersonal knowledge sharing occurs (Nahapiet \& Ghoshal, 1998). Moreover, each individual within a social network has their own unique set of resources that assists with knowledge sharing. Through everyday social interactions, employees are able to foster strong coworker relationships which increase the quality and quantity of knowledge sharing (Lane \& Lubatkin, 1998). Nahapiet \& Ghoshal (1998) define social capital with three dimensions: structural (the presence and configuration of social interaction ties between actors), relational (the types of personal relationships people have with one another), and cognitive (the collective goals and aspirations of the organization members). The structural dimension is illustrated by social interaction ties, the relational dimension is illustrated by trust, norm of reciprocity, and identification, and the cognitive dimension is illustrated by a shared vision and shared language (Chiu, Hsu, \& Wang, 2006; Nahapiet \& Ghoshal, 1998). 
From this perspective, the strength of these ties is important to understanding knowledge sharing. Social capital facilitates teamwork and reciprocity for mutual benefit (Putnam, 1995). For example, studies have shown that weak ties help transfer less complex knowledge but hindered the transfer of more complex knowledge (Hansen, 1999). Researchers have suggested that individuals are less willing to make the extra effort to transfer more complex knowledge to others with whom they have weak relationships (Wang \& Noe, 2010). Studies have also shown how social capital facilitates resource exchange, production innovation, and knowledge acquisition across various industries (Tsai \& Ghoshal, 1998; Yli-Renko, Autio, \& Sapienza, 2001). In virtual communities, the number of direct ties and personal relationships an individual has with others has been shown to increase the quantity and quality of knowledge shared (Chiu, Hsu, \& Wang, 2006; Wasko \& Faraj, 2005). Therefore, in hybrid virtual communities, where persons have an opportunity to meet face-to-face, we would expect similar, if not stronger, outcomes regarding knowledge sharing. These relationships are illustrated in our conceptual model in Figure 1 that guides the replication and extension of the Chiu et al. (2006) study.

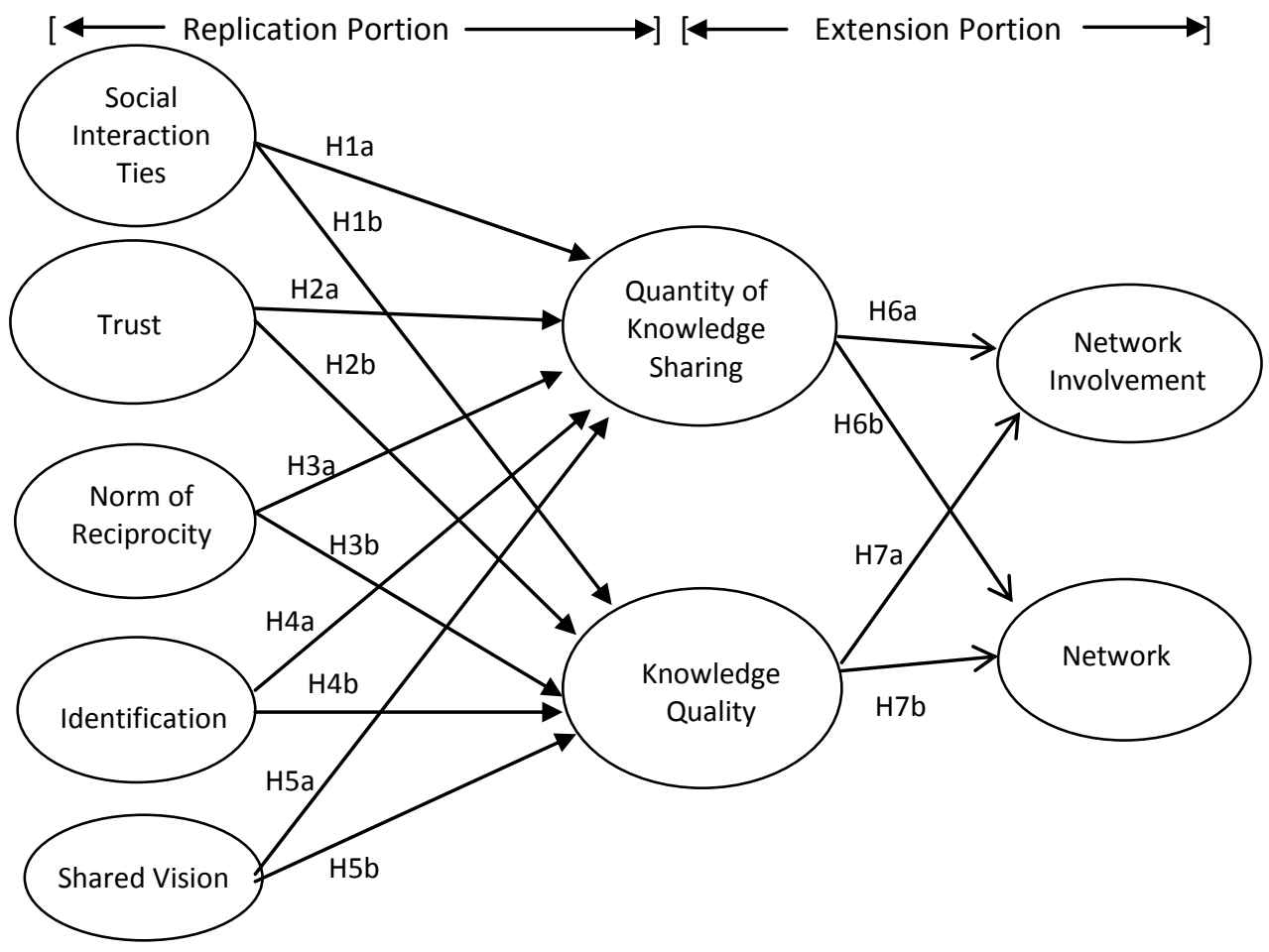

Figure 1. Replication and Extension Research Model for Knowledge Sharing in CELA Network 


\section{Hypotheses}

Since the present study is a replication and extension of the Chiu et al. (2006) study, we examine here the same set of hypotheses put forth by those authors with the exception of hypotheses related to outcome expectations. We have dropped those constructs from the model for our study and, instead, have incorporated two actual outcome variables resulting from knowledge sharing, and this represents our extension of the Chiu et al. (2006) model. However, in the interest of space conservation, we do not provide here the reasoning and rationale used in developing each of their hypotheses. The interested reader can refer to their study for details.

Additionally, we did not incorporate Chiu et al.'s (2006) construct of shared language in our own model because all of the participants were Russian speakers and had a common communication language. Given the age of the CELA Network, its culture, codes, acronyms, subtleties, and underlying assumptions is still evolving. Thus, the extent to which all of these are shared among Network members is questionable. Therefore, in examining the influence of social capital dimensions on knowledge sharing quantity and quality in the CELA Network, the following hypotheses were tested (cf. Chiu et al., 2006):

H1a. Members' social interaction ties are positively associated with their quantity of knowledge sharing.

H1b. Members' social interaction ties are positively associated with the quality of knowledge shared by them.

H2a. Trust is positively associated with the quantity of knowledge sharing.

H2b. Trust is positively associated with the quality of knowledge shared by the members.

H3a. Norm of reciprocity is positively associated with the quantity of knowledge sharing.

H3b. Norm of reciprocity is positively associated with the quality of knowledge shared by members.

H4a. Identification is positively associated with the quantity of knowledge sharing.

H4b. Identification is positively associated with the quality of knowledge shared by members.

H5a. Shared Vision is positively associated with the quantity of knowledge sharing.

H5b. Shared vision is positively associated with the quality of knowledge shared by members.

\subsection{Outcomes Resulting from Knowledge Sharing}


Recent studies relating knowledge sharing to individual and organizational outcomes are sparse. However, it is possible to draw some insights regarding these relationships from earlier studies. For example, Nelson \& Cooprider (1996) found that shared knowledge mediates the relationship between trust and influence and information systems performance and that increasing levels of shared knowledge (quantity) between information systems and line groups leads to increased information systems performance. Lee's (2001) study of the impact of knowledge sharing on information systems outsourcing success found that explicit knowledge sharing appeared to be a more effective way for outsourcing success than implicit knowledge sharing even though both are significant predictors. Lin (2007), who investigated firm innovation capability resulting from knowledge sharing processes, found that those employees who collect and donate knowledge positively influences firm innovation capability. Thus, based on these collective results, we hypothesize:

H6a. The quantity of knowledge sharing is positively related to the personal outcome of work involvement.

H6b. The quality of knowledge sharing is positively related to the personal outcome of work involvement.

H7a. The quantity of knowledge sharing is positively related to the personal outcome of increased network commitment.

H7b. The quality of knowledge sharing is positively related to the personal outcome of increased network commitment.

The professional network on which this research is based functions as a virtual community only part of the time. The members have a number of opportunities to meet one another through a series of face-to-face meetings and events (e.g., learning academies, reunion summits, mini-summits, local meetings and activities) throughout the year. These face-to-face meetings and events provide the mechanisms for members to become socially integrated into the network and form stronger ties at a much faster pace than would occur within a strict virtual community where members did not meet face-to-face. We discuss below the methods and results for our study.

\section{Method}

\subsection{Sample and Procedures}

A survey investigating the nature of involvement of members in the Central Eurasia Leadership Alliance (CELA) Network was administered to network members who attended a 2010 reunion of previous classes from the Leadership Academy sponsored by CELA. The Central Eurasia Leadership Alliance is an ambitious, multicultural initiative, promoting regional cooperation and fostering the development of tomorrow's most forward-thinking, mid-career leaders in the Caucasus, Central Asia and Afghanistan. Reflected in CELA's mission is the goal of 
building a transnational network of forward-thinking civil society, political, and business leaders who can help enhance regional cooperation, security and prosperity (EastWest Institute, 2002). Persons who are selected to attend the twoweek Leadership Academy become members of the CELA Network upon completion of the program. Communication among members from different countries occurs primarily via electronic means (email, SKYPE, etc.), while members within a particular country have an opportunity for face-to-face meetings on a periodic basis in addition to communicating electronically. As such, the CELA Network is not a strict virtual community but, rather, a hybrid virtual network.

Data were collected during the reunion meeting. Of the approximate 250 members in the Network, 121 members were present at the reunion, and 77 members returned completed surveys, making the response rate $31 \%$. The respondents were told that the purpose of the survey was to determine how different relationships within the Network were evolving over time and to ascertain the kinds of benefits members were deriving from the Network. Respondents were assured that their responses would remain anonymous. There were 35 men and 42 women ranging in age from 35 to 54 and they were from the nine Central Eurasian countries of the region (Afghanistan, Armenia, Azerbaijan, Georgia, Kazakhstan, Kyrgyzstan, Tajikistan, Turkmenistan, and Uzbekistan).

In this study, items used to operationalize the constructs were adapted from previous studies and modified for use in the knowledge-sharing context. For the replication portion of the study, the same measures used by Chiu et al. (2006) were used by us. Additionally, the measures used in the extension of their study were adapted from existing measures. All items were measured using a five-point or seven-point Likert scale (ranging from 1 = strongly disagree to 5 or $7=$ strongly agree). The measurement approach for each construct in the conceptual model is briefly described below.

\subsection{Measures}

\subsubsection{Independent Variables}

Social Interaction Ties. This construct involves a developing close relationships, spending time interacting with others, and frequently communicating with other members. It was measured using the four items used in the Chiu et al. (2006) study. A sample item from this scale is, "I maintain close social relationships with some members in the CELA Network."

Trust. Five items used by Chiu et al. (2006) to measure trust were included in our survey and the items reflected an individual's beliefs that other members would not engage in opportunistic behavior, that they would keep their promises, be truthful, and behave in a consistent manner. A sample item for this scale is, "Members in the CELA Network will always keep the promises they make to one another." 
Norm of Reciprocity. Two items were used to measure this construct, following Chiu et al. (2006), and the measure reflects the fairness of knowledge sharing between members. A sample item for this scale is, "I know that other members in the CELA Network will help me, so it's only fair to help other members."

Identification. This measure captures an individual's positive feelings toward the Network, a sense of belonging, and a feeling of togetherness all of which were assessed with four items used by Chiu et al. (2006). A sample item is, "I feel a sense of belonging towards the CELA Network."

Shared Vision. This construct measured an individual's perceptions of whether Network members share the same vision, goal, and values about knowledge sharing and was measured with three items, following Chiu et al. (2006). A sample item is, "Members in the CELA Network share the same goal of learning from each other."

\subsubsection{Mediating Variables}

Knowledge Quality. Six attributes of the content of shared knowledge are reflected in this measure: timeliness, completeness, reliability, accuracy, relevance, and ease of understanding, and these attributes were captured with adaptations of the six items used by Chiu et al. (2006). A sample item is, "The knowledge shared by members in the CELA Network is accurate."

Knowledge Quantity. Quantity of knowledge shared was based on the average volume (frequency) of an individual's knowledge sharing per month and was measured with a seven-point scale where $1=$ less than once per month, 2 = about once per month, 3 = about twice per month, 4 = about four times per month, $5=$ about eight times per month, $6=$ about 16 times per month, and $7=$ more than 30 times per month.

\subsubsection{Dependent Variables}

Network Involvement. Six items from Lodhal and Kejner's (1965) Job Involvement Survey were adapted for use in this study to measure the extent of a member's Involvement in the CELA Network. A sample item is, "I am very much involved personally with CELA."

Network Commitment. Mowday, Steers, \& Porter's (1979) six-item Organizational Commitment scale was adapted for use in this study to measure a member's level of commitment to the CELA Network. A sample item is, "I am proud to tell others that I am part of the CELA network."

\subsection{Analysis Methods}

To test the research model we examined the hypotheses using structural equation modeling (SEM). We first examined the convergent validity of the measurement items by conducting within-scale factor analysis to determine whether the 
measurement items converged onto their constructs with a reasonably high factor loading (greater than .70). Additionally, the reliability of our measurement items was examined by computing composite reliabilities for each construct. The test of the research model was carried out using single-indicator structural equation modeling (SEM) which tests a model and its validity simultaneously. Singleindicator SEM was used because of the limited size of the sample and the need to conserve degrees of freedom.

With single-indicator SEM, the measurement parameters were fixed prior to the analyses. More specifically, the path (factor loading) from any construct to its measured variable was set equal to the square root of the reliability of the measured variable, whereas the amount of random error variance was set equal to the quantity: (one minus the reliability) (Kenny, 1979). These procedures overcome some of the biasing effects of method variance and random measurement error in path analysis (Billings \& Wroten, 1978). The intercorrelations among constructs and estimates of random error variance served as input for LISREL 8.7 (Joreskog \& Sorbom, 2001), which provides maximum likelihood estimates of the parameters that are not fixed as well as goodness-of-fit measures. Because the constructs of interest were based on single indicators, only the structural equation model was evaluated for goodness of fit.

\subsection{Assessment of Model Fit}

Due to the fact that there is no one definitive test of significance for model indices, we followed Hu \& Bentler's (1999) recommendations to use multiple indices to evaluate overall model fit. Overall model fit was assessed by three fit indices: comparative fit index (CFI $\geq 0.95$ ) (Bentler, 1990); normed fit index (NFI $\geq 0.90$ ) (Bentler \& Bonnett, 1980); and standardized root mean square residual (SRMSR $\leq$ 0.08) (Hu \& Bentler, 1999; Browne \& Cudeck, 1993). We also report the Chi Square values and root mean square error approximation (RMSEA) as references for model fit as well.

\section{Results}

The constructs of interest in this study were measured using established scales found in the extant knowledge sharing, social capital, and management literatures. Table 1 presents means, standard deviations, composite reliabilities, average variance extracted estimates (AVE), and correlations among the study variables. The intercorrelations presented in Table 1 and estimates of random error variance (1 - reliability) served as input for LISREL 8.7 (Joreskog \& Sorbom, 2001). We used LISREL 8.7 to examine the relationships among the study variables.

Assessment of validity of our measures was not done in the customary manner because we did not perform confirmatory factor analysis on our measures due to the size of our sample. Rather, convergent validity was evaluated two ways: (1) using the Kaiser-Meyer-Olkin (KMO) index for which values greater than 0.50 are 
considered satisfactory (Lucian, Barbosa, de Sousa Filho, Pereira, \& da Silva, 2008), and (2) calculating composite reliabilities and average variance extracted (AVE) using procedures suggested by Fornell and Larcker (1981), wherein an AVE index with values greater than or equal to 0.50 is considered satisfactory (Chin, 1998). As seen from Table 1, all but two of the KMO indices are at least equal to the minimum threshold of 0.50 , and all composite reliabilities are above the recommended minimum threshold of 0.70 . Together, these indices suggest that conditions for convergent validity are met.

If a measurement is distinct and empirically different from other measurements, then discriminant validity has been demonstrated. In Table 1, we see that all values of the square root of AVE on the diagonal are greater than the inter-construct correlations below or to the left of the AVE value in each row. According to Bargozzi, Yi, \& Phillips (1991), the condition for discriminant validity is fulfilled and hence the measures should have sufficient construct validity.

Therefore, in light of the psychometric qualities of the study constructs and their descriptive statistics, we conclude that the measurements are sound and thus it is appropriate to use them for testing the hypotheses.

\section{Table 1. Means, Standard Deviations, Composite Reliabilities, AVE, and Intercorrelations among Measures*}

\begin{tabular}{lllllllllllll}
\hline Variables & C.R. & AVE & KMO & 1 & 2 & 3 & 4 & 5 & 6 & 7 & 8 & 9 \\
\hline KSSIT & .90 & .99 & .781 & .99 & & & & & & & & \\
KSNOR & .77 & .98 & .500 & .53 & .98 & & & & & & & \\
INDENTIFI & .86 & .99 & .795 & .44 & .42 & .99 & & & & & & \\
TRUST & .86 & .99 & .745 & .08 & .16 & .44 & .99 & & & & & \\
SHRDVIS & .88 & .99 & .743 & .17 & .22 & .58 & .64 & .99 & & & & \\
KNOWQUAL & .90 & .91 & .867 & .27 & .19 & .56 & .65 & .70 & .91 & & & \\
KNOWQUAN & .86 & .99 & .500 & .32 & .17 & .06 & .17 & .18 & .20 & .99 & & \\
INVOLVE & .79 & .94 & .787 & .54 & .31 & .61 & .23 & .38 & .43 & .46 & .96 & \\
COMMIT & .74 & .96 & .748 & .45 & .37 & .59 & .19 & .37 & .38 & .25 & .68 & .94 \\
\hline Means & & & & 5.53 & 5.60 & 5.82 & 4.64 & 5.10 & 4.87 & 3.20 & 3.86 & 5.65 \\
Std. Dev & & & & 1.28 & 1.28 & 1.00 & 1.04 & 1.00 & 0.91 & 1.80 & 0.65 & 0.85 \\
\hline
\end{tabular}

Note: *The values in the diagonal (bolded) represent the square root of the construct's average variance extracted (AVE) and the off-diagonal values are the inter-construct correlations.

\subsection{Results of Hypotheses tests}

The path coefficients obtained with LISREL 8.7 for the replicated portion of the research model are summarized in Table 2, while the path coefficients obtained for the extended portion of our research model are summarized in Tables 3 and 4 for network involvement as an outcome variable and network commitment as an outcome variable, respectively. The results reported in these tables are illustrated graphically in Figure 2, Figure 3a, and Figure 3b, respectively. Only statistically significant paths are shown in the figures for greater clarity in assessing the outcomes of the hypothesis testing. 
As seen in Table 2 and Figure 2, the path coefficient between social interaction ties and quantity of knowledge sharing (.69) is statistically significant and positive, thereby providing support for $\mathrm{H} 1 \mathrm{a}$. The path coefficient between identification and quantity of knowledge sharing (-.83) is statistically significant but negative - which is opposite the prediction of $\mathrm{H} 4 \mathrm{a}$. Therefore $\mathrm{H} 4 \mathrm{a}$ is not supported. The path coefficients between trust and quality of knowledge sharing (.31) and between shared vision and quality of knowledge sharing (.40) are both statistically significant and positive, thereby providing support for $\mathrm{H} 2 \mathrm{~b}$ and $\mathrm{H} 5 \mathrm{~b}$, respectively. All other paths in the model in Figure $1 \mathrm{~b}$ were not statistically significant, thereby rendering $\mathrm{H} 1 \mathrm{~b}, \mathrm{H} 2 \mathrm{a}, \mathrm{H} 3 \mathrm{a}, \mathrm{H} 3 \mathrm{~b}, \mathrm{H} 4 \mathrm{~b}$, and $\mathrm{H} 5 \mathrm{a}$ not supported. Indeed, for our analysis, only three of 10 hypotheses were supported - namely $\mathrm{H} 1 \mathrm{a}, \mathrm{H} 2 \mathrm{~b}$, and $\mathrm{H} 5 \mathrm{~b}$. The social capital dimension, norm of reciprocity, was not a significant predictor of either knowledge sharing quantity or knowledge sharing quality.

\section{Table 2. Maximum Likelihood Estimates for Research Model: Replicated Results}

\begin{tabular}{lcccc}
\hline Paths and Hypotheses & Estimate & $t$ value & $p^{*}$ & Support \\
\hline H1a. Soc. Interaction Ties -> KS Quantity & .69 & 2.92 & .004 & Y \\
H1b. Soc. Interaction Ties -> KS Quality & .14 & 1.75 & .22 & $N$ \\
H2a. Trust -> KS Quantity & .29 & 0.82 & .25 & $N$ \\
H2b. Trust -> KS Quality &. $\mathbf{3 1}$ & 2.53 & .01 & $\mathbf{Y}$ \\
H3a. Norm of Reciprocity -> KS Quantity & .03 & 0.13 & .90 & $N$ \\
H3b. Norm of Reciprocity - > KS Quality & -.10 & -1.23 & .22 & $\mathbf{N}$ \\
H4a. Identification -> KS Quantity & -.83 & -2.05 & .04 & $N$ \\
H4b. Identification -> KS Quality & .12 & 0.89 & .38 & $N$ \\
H5a. Shared Vision - KS Quantity & .53 & 1.17 & .25 & N \\
H5b. Shared Vision -> KS Quality &. $\mathbf{4 0}$ & 2.59 & .01 & Y \\
\hline
\end{tabular}

* One-tailed test

Table 3 and Figure 3a contain the results of testing the extension of Chiu et al.'s (2006) model with Network involvement as an outcome variable. The initial pattern of results for the replicated portion of the model mirrored that of Figure 2 with respect to which paths were statistically significant. However, the SEM results for Figure $3 a$ (modification indices) suggested that model fit could be improved if an error covariance between identification and Network involvement were added to the model. As seen from the fit indices provided in Figure 3a, model fit improved substantially with CFI increasing from 0.90 to 0.96 , NFI increasing from 0.89 to 0.95 , and SRMSR decreasing from 0.08 to 0.07 . As such, the final results for the model shown in Figure $3 a$ indicated that the path from social interaction ties to knowledge sharing quality (.16) became significant, thereby supporting $\mathrm{H} 1 \mathrm{~b}$. Hypotheses $\mathrm{H} 1 \mathrm{a}, \mathrm{H} 2 \mathrm{~b}$, and $\mathrm{H} 5 \mathrm{~b}$ also remained supported. However, the significant negative path from identification to knowledge sharing quantity was no longer significant. Further, Figure $3 a$ shows that the paths from knowledge sharing quantity to Network involvement (.15) and from knowledge sharing quality to Network involvement (.30) are both statistically significant and positive, thereby supporting $\mathrm{H} 6 \mathrm{a}$ and $\mathrm{H} 6 \mathrm{~b}$. 


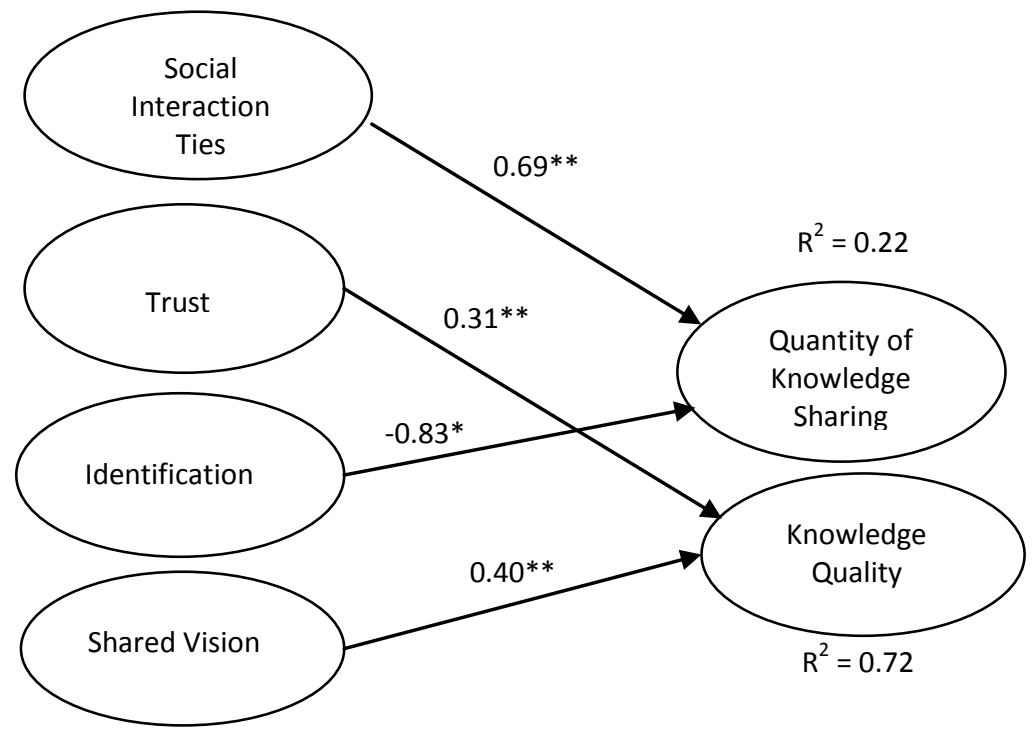

Figure 2. Replication Results for CELA Network Study

${ }^{*} p<.05, * * p<.01 .\left(x^{2}=0.04, \mathrm{CFI}=1.00, \mathrm{NFI}=1.00\right.$, SRMSR $\left.=0.00, \mathrm{RMSEA}=0.00\right)$

Table 3. Maximum Likelihood Estimates for Research Model: Extended Results - Involvement

\begin{tabular}{|c|c|c|c|c|}
\hline Paths and Hypotheses & Estimate & $t$ value & $p^{*}$ & Support \\
\hline H1a. Soc. Interaction Ties -> KS Quantity & .58 & 2.62 & .03 & $\mathbf{Y}$ \\
\hline H1b. Soc. Interaction Ties -> KS Quality & .16 & 2.24 & .02 & $\mathbf{Y}$ \\
\hline H2a. Trust -> KS Quantity & .33 & 0.91 & .37 & $N$ \\
\hline H2b. Trust -> KS Quality & .27 & 2.26 & .03 & $\mathbf{Y}$ \\
\hline H3a. Norm of Reciprocity -> KS Quantity & -.00 & -0.02 & .98 & $N$ \\
\hline H3b. Norm of Reciprocity -> KS Quality & -.10 & -1.33 & .19 & $N$ \\
\hline H4a. Identification -> KS Quantity & -.57 & -1.52 & .37 & $N$ \\
\hline H4b. Identification -> KS Quality & .16 & 1.35 & .18 & $N$ \\
\hline H5a. Shared Vision -> KS Quantity & .35 & 0.83 & .41 & $N$ \\
\hline H5b. Shared Vision -> KS Quality & .40 & 2.88 & .004 & $\mathbf{Y}$ \\
\hline H6a. KS Quantity -> Network Involvement & .15 & 3.98 & .000 & $\mathbf{Y}$ \\
\hline H6b. KS Quality -> Network Involvement & .30 & 3.61 & .000 & $\mathbf{Y}$ \\
\hline
\end{tabular}

Table 4 and Figure $3 b$ contain the results of testing the extension of Chiu et al.'s (2006) model with Network commitment as an outcome variable. The initial pattern of results for the replicated portion of the model again mirrored the results of Figure 2 with respect to which paths were statistically significant. However, the SEM results for Figure $3 \mathrm{~b}$ (modification indices) also suggested that model fit could be improved if a path between social interaction ties and Network commitment were added to the model. 
David L. FORD, Laurie L. ZIEGLER, Ray FANG \& Oscar HOLMES IV

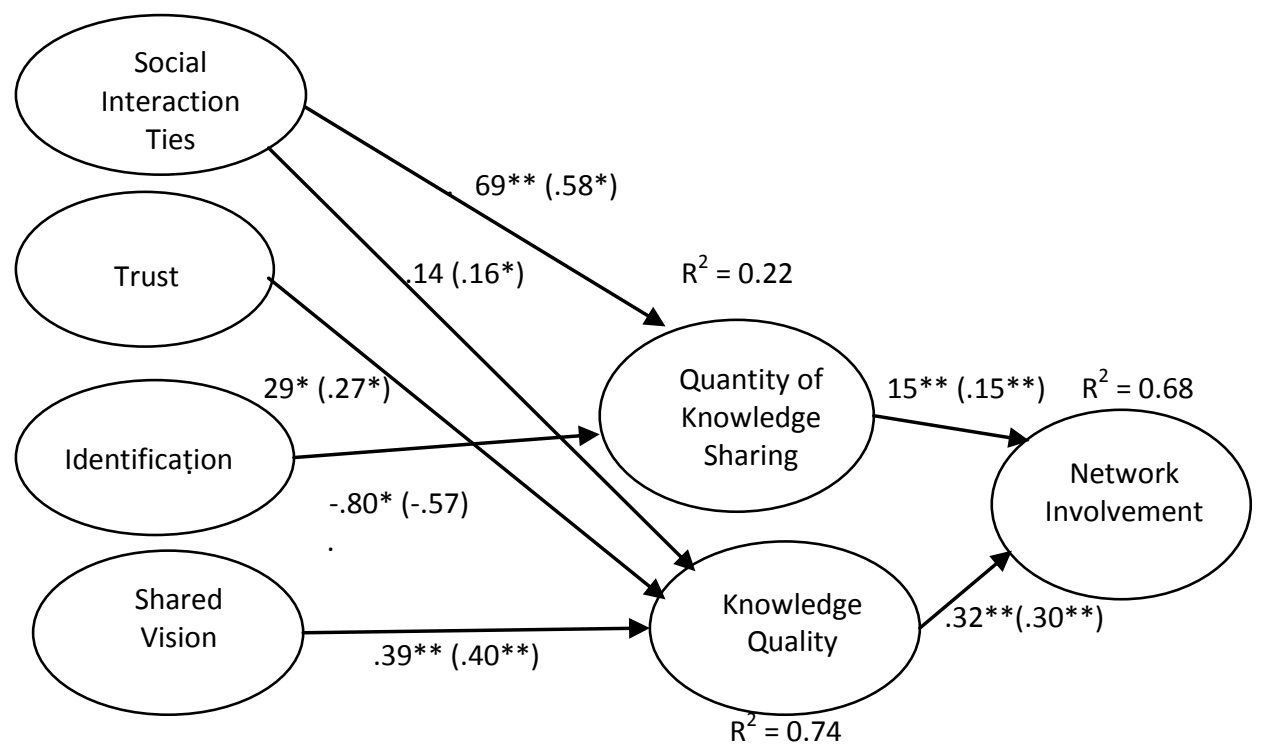

Figure 3a. Research Extension Results for Network Involvement as

\section{Outcome Variable}

$* p<.05, * * p<.01$; values in parentheses are estimates for revised model $\left(\chi^{2}=35.25, \mathrm{CFI}=0.90, \mathrm{NFI}=0.89, \mathrm{SRMSR}=0.08, \mathrm{RMSEA}=0.26\right)$

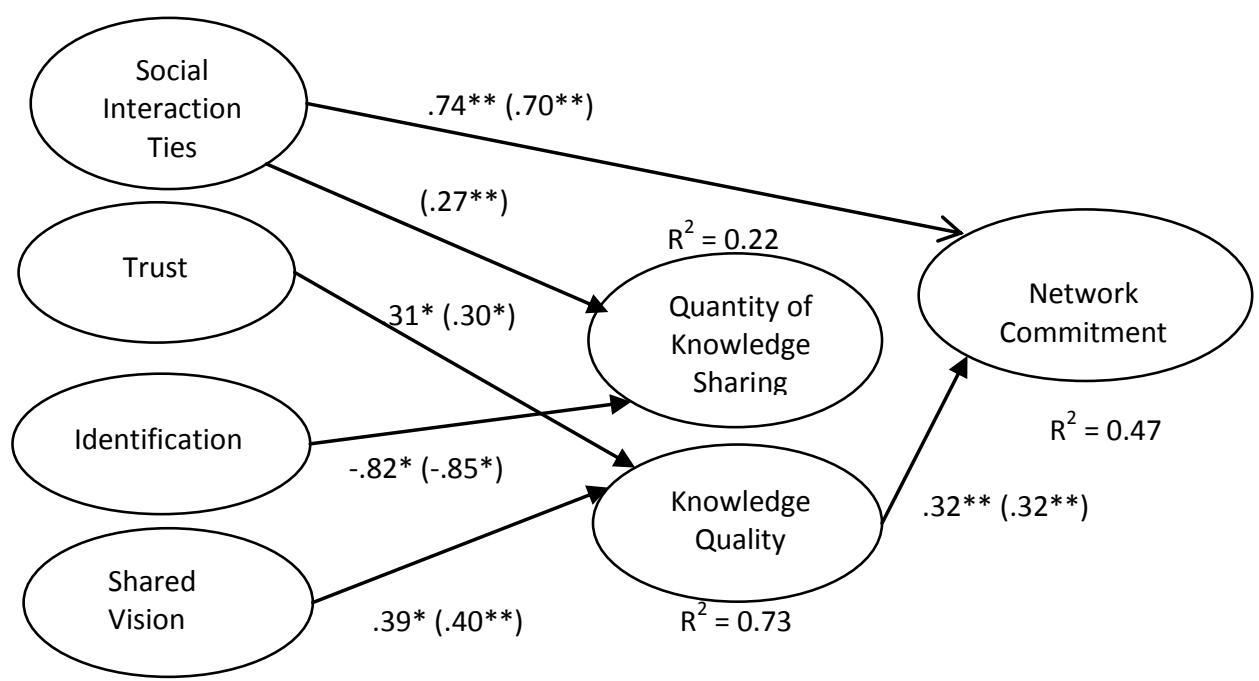

Figure 3b. Research Extension Results for Network Commitment as

\section{Outcome Variable}

${ }^{*} \mathrm{p}<.05,{ }^{*} \mathrm{p}<.01 ;\left(\chi^{2}=25.52, \mathrm{CFI}=0.93, \mathrm{NFI}=0.92, \mathrm{SRMSR}=0.09, \mathrm{RMSEA}=0.21\right)$ 
Table 4. Maximum Likelihood Estimates for Research Model: Extended Results - Commitment

\begin{tabular}{|c|c|c|c|c|}
\hline Paths and Hypotheses & Estimate & $\mathrm{t}$ value & $p^{*}$ & Support \\
\hline H1a. Soc. Interaction Ties -> KS Quantity & .70 & 2.97 & .003 & $\mathrm{Y}$ \\
\hline H1b. Soc. Interaction Ties -> KS Quality & .13 & 1.61 & .11 & $\mathrm{~N}$ \\
\hline H2a. Trust -> KS Quantity & .30 & 0.84 & .40 & $\mathrm{~N}$ \\
\hline H2b. Trust -> KS Quality & .30 & 2.45 & .02 & $\mathbf{Y}$ \\
\hline H3a. Norm of Reciprocity -> KS Quantity & .02 & 0.10 & .92 & $\mathrm{~N}$ \\
\hline H3b. Norm of Reciprocity -> KS Quality & -.09 & -1.20 & .23 & $\mathrm{~N}$ \\
\hline H4a. Identification -> KS Quantity & -.85 & -2.08 & .04 & $\mathbf{N}$ \\
\hline H4b. Identification -> KS Quality & .14 & 1.05 & .30 & $\mathrm{~N}$ \\
\hline H5a. Shared Vision -> KS Quantity & .53 & 1.17 & .24 & $\mathrm{~N}$ \\
\hline H5b. Shared Vision -> KS Quality & .40 & 2.61 & .01 & $\mathbf{Y}$ \\
\hline H7a. KS Quantity -> Network Involvement & .03 & 0.59 & .56 & $\mathrm{~N}$ \\
\hline H7b. KS Quality -> Network Involvement & .32 & 2.70 & .007 & $\mathbf{Y}$ \\
\hline Soc. Interaction Ties -> Network Commitment & .27 & 3.29 & .001 & + \\
\hline
\end{tabular}

* One-tailed test. + Path was not hypothesized

As seen from the fit indices provided in Figure $3 \mathrm{~b}$, model fit improved substantially with CFI increasing from 0.93 to 0.96 , NFI increasing from 0.92 to 0.95 , and SRMSR decreasing from 0.09 to 0.04 . It is worth noting that the final significant path between knowledge sharing quantity and Network involvement in Figure 3a was not significant for the comparable path in Figure $3 \mathrm{~b}$ between knowledge sharing quantity and Network commitment in the revised model, whereas the direct path between social interaction ties and Network commitment is significant and positive (.27). Apparently, knowledge sharing quantity does not mediate the relationship between social interaction ties and Network commitment, so $\mathrm{H7a}$ was not supported. The path between knowledge sharing quality and Network commitment is positive and significant (.32), thereby supporting $\mathrm{H} 7 \mathrm{~b}$.

Overall, the Chiu et al. (2006) study showed that six of 10 paths examined in the present study exhibited $P$-values less than 0.05 and the other four paths were not significant at the 0.05 level, while four of 10 paths examined in the present study were significant at the 0.05 level. The results for our extension of the Chiu et al. (2006) study showed that six of 12 paths exhibited $P$-values less than 0.05 when Network involvement was the outcome variable. On the other hand, only four of 12 paths exhibited $P$-values less than 0.05 when Network commitment was the outcome variable. Additionally, for Network commitment, social interaction ties displayed a strong and significantly positive direct relationship with Network commitment. This linkage was suggested by the modification indices associated with the SEM analysis. No direct linkages between the social capital constructs and the outcome variables had been hypothesized originally.

Figures $3 a, 3 b$ and 4 show the explanatory power of the research models. For example, for the replicated model in Figure 3a, the R-square values show that the significant social capital factors account for $22 \%$ of variance of knowledge sharing 
quantity and $74 \%$ of variance of knowledge sharing quality. This compares favorably to the percentages of explained variance found in the Chiu et al. (2006) study ( $17 \%$ and $64 \%$, respectively). For our extended results, knowledge sharing quantity and knowledge sharing quality account for $68 \%$ of the variance in Network involvement (Figure 3a), while knowledge sharing quantity and quality, along with social interaction ties, account for $47 \%$ of the variance in network commitment.

These results are discussed below along with limitations and directions for future research.

\section{Discussion}

In the present study, we examined the determinants of knowledge sharing quantity and knowledge sharing quality in a professional hybrid virtual network from the Central Eurasian region. From a cultural context, the study is unique because few studies have examined knowledge sharing behavior in this corner of the globe. As a professional community of leaders, the network examined in this study is relatively young and still evolving, whereby the influence of social capital factors and social cognitive factors on knowledge sharing behavior may be less understood compared to that in an established virtual community.

The purpose of this study was to replicate and extend the examination of social capital and social cognitive factors on knowledge sharing quantity and knowledge sharing quality that had first been reported by Chiu and his colleagues in 2006 (cf. Chiu et al., 2006). However, rather than using a strict virtual network of members the present study examines relationships between social capital factors and knowledge sharing within a hybrid virtual network. We have labeled the network as a hybrid network because members of the network do have opportunities to interact face-to-face with other members through various network structures (training academies, summits, cultural exchanges, and reunions) that occur from time to time. Therefore, examining knowledge sharing within the hybrid network represents another unique aspect of the study.

With this in mind, we proposed two outcome variables resulting from knowledge sharing quantity and knowledge sharing quality, namely, network involvement and network commitment of the members. We chose these outcomes because we believe they are especially relevant for gaining insights regarding the development of social interaction and member-member ties embedded in the configuration of linkages among members of the Network. For example, Wellman \& Worthy (1990) have shown that knowledge exchange is facilitated by strong community ties which could, in turn, affect commitment to the Network. Likewise, Dholakia, Bagozzi, and Pearo (2004) have shown that members' intentions to participate in virtual communities are strongly affected by group norms, which could, in turn, affect one's level of involvement in the Network.

Our results showed that social capital factors that affect both knowledge sharing 
quantity and knowledge sharing quality in online virtual professional communities differentially affect one or the other but not both in hybrid professional networks where members have experienced some face-to-face contact with other members of the network. An exception to this appears to be the relationship between social interaction ties and knowledge sharing quantity and quality when network involvement is examined as an outcome of knowledge sharing quantity and quality simultaneously. However, when network commitment is an outcome variable, social interaction ties positively impact members' quantity of knowledge sharing but not knowledge quality. This is particularly interesting because scholars have proposed that as a network relationship matures, the nature of the relationship evolves from being purely instrumental to both instrumental and social (Porter \& Woo, 2015). Social exchange theory suggests that with network commitment as the outcome variable, we would expect knowledge quality to be a stronger predictor than knowledge quantity because as relationship ties grow stronger, networking interactions would be conducted with a mutual and/or other interest rather than a purely economic exchange (Cropanzano \& Mitchell, 2005). As such, these quality exchanges would manifest themselves through network commitment.

All things considered, perhaps the psychological distance inherent in hybrid networks is a boundary condition that prevents exchange relationships to evolve past a purely instrumental and self-interested orientation. For instance, it may be difficult for network members to form truly social relationships given their infrequent meetings and physical distance from one another. They may feel less connected to other members. Therefore, it may be that network members see knowledge sharing as a series of economic exchanges that, in turn, build commitment. Our findings may highlight the importance of looking at psychological distance as a moderator of how people develop and conduct social exchange relationships.

Also, reciprocity was found not to have any influence on knowledge sharing behavior at all in our hybrid network. Chiu et al. (2006) undertook additional SEM analyses to probe further into the impact of reciprocity and identification on knowledge quality sharing behavior. Their additional results indicated that norm of reciprocity and identification exerted strong and positive effects on trust. They speculated that perhaps "norm of reciprocity and identification have indirect effects on knowledge quality via trust" (Chiu et al., 2006, p. 1883). Certainly, this might be a fruitful avenue to pursue in future studies with larger samples. Nevertheless, the present study's results add to an emerging body of empirical work focused on organizations in the Central Eurasian region (cf. Ismail, Ford, \& Ferriera, 2008; Ismail, Ford, Wu, \& Peng, 2013; Ford \& Ismail, 2006, 2008).

\subsection{Limitations}

The present study is not without its limitations and faults. First, the small sample size $(N=71)$ necessitated that we use single-indicator SEM rather that an analytical 
approach that examined the measurement model involving all of the items associated with the measures used in the study as well as undertaking a confirmatory factor analysis of the measures. Second, because of the cultural context of our sample and its hybrid nature, we cannot generalize our results to other cultural contexts or professional virtual communities. However, we believe the cultural context of the study is also one of its strengths. The subject network for the present study is a regional network as opposed to a global network of members and, as Chiu et al. (2006) observed, knowledge sharing in global virtual communities of practice might be different from that of intra-organizational virtual communities. The cross-sectional nature of our study is a further limitation that should be addressed in future studies via longitudinal designs that would allow for the capture of the dynamic nature of emerging knowledge sharing behavior in the network. Finally, our study only addressed one-directional knowledge sharing behavior. Further studies could possibly examine bi-directional (e.g., knowledge donating and knowledge receiving) knowledge sharing behaviors and the factors that influence each type (cf. Tangaraja, Mohd Rasdi, Ismail, \& Samah, 2015).

\subsection{Implications for Research and Practice}

Our study presents several implications for research and practice. For scholars, previous literature has suggested that the Internet may both increase and decrease social capital (Putnam, 1995; Wellman et. al. 2001). In fact Uslaner, (2000) has claimed that the Internet does neither. In theory, the norm of reciprocity should have a much stronger influence on knowledge sharing in hybrid versus virtual networks. Aware of eventual face-to-face contact, participants may be more inclined to reciprocate knowledge sharing in fear of appearing normatively deviant. However, hybrid networks may present a unique factor involving reciprocity. For example, perhaps the friendly nature of face-to-face meetings may reduce the psychological distance between network members, thereby reducing participants' perception of immediate obligation towards reciprocating back to network members compared to a purely virtual network. In other words, norms of reciprocity may not be consciously influencing behavior, but still does so unconsciously. Teasing apart these differences is beyond the scope of our study. Future studies may wish to investigate the extent to which psychological distance influences reciprocity across different cultures.

Our results also present several implications for managers. First, by replicating Chiu et. al. (2006), we provide additional evidence that knowledge sharing increases network involvement. As such, managers of virtual or hybrid communities should encourage members to frequently communicate knowledge and new ideas amongst each other. This could create a feedback loop such that knowledge sharing increases network involvement, thereby increasing further knowledge sharing. Additionally, while the present study examined the quality and quantity of knowledge sharing in general, managers may benefit from future studies that focus on explicit and tacit forms of knowledge sharing (see, e.g., Ma et al., 2014). 
Second, managers should seek to urge more senior network members to begin knowledge sharing. Our studies reveal that the quality of knowledge shared was a much stronger predictor of beneficial outcomes than the quantity of knowledge shared. Accordingly, members of the virtual network should be motivated both intrinsically and extrinsically to provide new ideas and solutions to existing problems and future opportunities. Praising network members for knowledge sharing would additionally strengthen the feedback loop.

Lastly, our findings reveal that social network ties are the strongest predictor of knowledge sharing. Though this may be difficult for virtual networks, managers should seek to strengthen the ties of network members through friendly interactions, video chat meetings, and if possible, face-to-face interactions. Thus, the development and maintenance of a hybrid or virtual community depends not on mere social capital factors and knowledge sharing, but how managers create environments that support such behaviors.

\section{References}

Bagozzi, R. P., Yi, Y., \& Phillips, L. W. (1991). Assessing construct validity in organizational research. Administrative Science Quarterly, $36 \quad$ (3), 421-458. https://doi.org/10.2307/2393203

Bandura, A. (1997). Self-efficacy: The exercise of control. Freeman, New York, NY.

Bandura, A. (1989). Social cognitive theory. Annals of child development. Jai Press LTD, Greenwich, CT, 1-60.

Bentler, P. M. (1990). Comparative fit indexes in structural models. Psychological Bulletin, 107, 238-246. https://doi.org/10.1037/0033-2909.107.2.238

Bentler, P. M. \& Bonnett, D. G. (1980). Significance tests and goodness of fit in the analysis of covariance structures. Psychological Bulletin, 88, 588-606. https://doi.org/10.1037/0033$\underline{2909.88 .3 .588}$

Billings, R. S. \& Wroten, S. P. (1978). Use of path analysis in industrial organizational psychology: Criticisms and suggestions. Journal of Applied Psychology, 63, 677-688. https://doi.org/10.1037/0021-9010.63.6.677

Bock, G. W., \& Kim Y.G. (2002). Breaking the myths of rewards: An exploratory study of attitudes about knowledge sharing. Information Resources Management Journal, 15(2), 1421. https://doi.org/10.4018/irmj.2002040102

Bock, G. W., Zmud R. W., Kim, Y.G., \& Lee, J.N .(2005). Behavioral intention formation in knowledge sharing: Examining the roles of extrinsic motivators, social-psychological forces, and organizational climate. MIS Quarterly, 29(1), 87-111. https://doi.org/10.2307/25148669

Browne, M. W. \& Cudeck, R. (1993). Alternative ways of assessing model fit. In K. A. Bollen and J. S. Ling (Eds.). Testing structural models (pp. 136-162). Newbury Park, CA: Sage.

Brown, J. S., \& Duguid, P. (1998). Organizing knowledge. California Management Review, 40(3), 90-111. https://doi.org/10.2307/41165945

Chin, W. W. (1998). Issues and opinions on structural equation modeling. MIS Quarterly, 22 (1), 7-16. https://doi.org/10.1016/j.dss.2006.04.001 
Chiu, C., Hsu, M., \& Wang, E.T. (2006). Understanding knowledge sharing in virtual communities: An integration of social capital and social cognitive theories. Decision Support Systems, 42, 1872-1888.

Connelly, C. E., \& Kelloway, E. K. (2003). Predictors of employees' perceptions of knowledge sharing cultures. Leadership \& Organization Development Journal, 24 (5/6), 294-301. https://doi.org/10.1108/01437730310485815

Cropanzano, R., \& Mitchell, M. S. (2005). Social exchange theory: An interdisciplinary review. Journal of Management, 46, 740-751. https://doi.org/10.1177/0149206305279602

Cross, R., \& Prusak, L. (2002). The people who make organizations go-or stop. Harvard Business Review, 80, 104-112.

Cummings, J. N. (2004). Work groups, structural diversity, and knowledge sharing in a global organization. Management Science, 50(3), 352-364. https://doi.org/10.1287/mnsc.1030.0134

Damodaran, L., \& Olphert, W. (2000). Barriers and facilitators to the use of knowledge management systems. Behaviour \& Information Technology, 19(6), 405-413. https://doi.org/10.1080/014492900750052660

Davenport, T. H., \& Prusak, L. (1998). Working knowledge: How organizations manage what they know. Boston, MA: Harvard Business School Press.

Dholakia, U. M., Bagozzi, R. P., \& Pearo, L. K. (2004). A social influence model of consumer participation in network- and small-group-based virtual communities. International Journal of Research in Marketing, 21(3), 241-263. https://doi.org/10.1016/j.ijresmar.2003.12.004

Ford, D. \& Ismail, K. (2006). Perceptions of effective leadership among Central Eurasian managers: A cultural convergence - divergence examination within a globalization context. Journal of International Management, 12(2), 158-180. https://doi.org/10.1016/j.intman.2006.02.013

Ford, D. \& Ismail, K. (2008). Perceived leader effectiveness across organizational roles: Exploratory evidence from Central Eurasia. Eurasian Journal of Business and Economics, 1(2), 131-156.

Fornell, C. \& Larcker, D. F. (1981). Evaluating structural equation models with unobservable variables and measurement error. Journal of Marketing Research, 18(1), 39-50. https://doi.org/10.2307/3151312

Grant, R. M. (1996). Toward a knowledge-based theory of the firm. Strategic Management Journal, 17, 109-122. https://doi.org/10.1002/smi.4250171110

Hansen, M. T. (1999). The search-transfer problem: The role of weak ties in sharing knowledge across organization subunits. Administrative Science Quarterly, 44(1), 82-111. https://doi.org/10.2307/2667032

Hu, L. \& Bentler, P. (1999). Cutoff criteria for cut indexes in covariance structure analysis: Conventional criteria versus new alternatives. Structural Equation Modeling, 6, 1-55. https://doi.org/10.1080/10705519909540118

Ismail, K., Ford, D., \& Ferreira, P. (2008). Organizational responses to institutional upheaval by Central Eurasian firms and the ability to transform under uncertainty. Journal of Asia Business Studies, 2(2), 1-12. https://doi.org/10.1108/15587890880000404 
Ismail, K. \& Ford, D., Wu, Q., \& Peng, M. (2013). Managerial ties, strategic initiatives, and firm performance in Central Asia and the Caucasus. Asia Pacific Journal of Management, 30, 433-446.

Joreskog, K. G. \& Sorbom, D. (2001). LISREL 8.7: Structural equation modeling with SIMPLIS command language. Chicago, IL: Scientific Software International.

Kankanhalli, A., Tan, B. C. Y., \& Wei, K. -K. (2005). Contributing knowledge to electronic knowledge repositories: An empirical investigation. MIS Quarterly, 29(1), 113-143. https://doi.org/10.2307/25148670

Kwok, S.H., \& Gao, S. (2005). Attitude towards knowledge sharing behavior. The Journal of Computer Information Systems, 46(2), 45-51.

Lane, P.J, \& Lubatkin, M. (1998). Relative absorptive capability and interorganizational learning. Strategic Management Journal, 19(5), 461-477. https://doi.org/10.1002/(SICI)1097-0266(199805)19:5<461::AID-SMJ953>3.0.CO;2-L

Lucian, R., Barbosa, G., de Sousa Filho, J., Pereira, F., \& da Silva, I. (2008). What do strategists have in their minds? The use of structural equation modeling to understand the strategy process. Brazilian business Review, 5(2), 86-102. https://doi.org/10.15728/bbr.2008.5.2.1

Ma, Z., Huang, Y., Wu, J., Dong, W., \&Qi, L. (2014). What matters for knowledge sharing in collectivistic cultures? Empirical evidence from China. Journal of Knowledge Management, 18 (5), 1004-1019. https://doi.org/10.1108/JKM-06-2014-0252

McFadyen, M. A., \& Cannella, A. A., Jr. (2004). Social capital and knowledge creation: Diminishing returns of the number and strength of exchange relationships. Academy of Management Journal, 47, 735-746. https://doi.org/10.2307/20159615

Michailova, S., \& Minbaeva, D.B., (2012). Organizational values and knowledge sharing in multinational corporations: The Danisco case. International Business Review, 21, 59-70. https://doi.org/10.1016/j.ibusrev.2010.11.006

Morrison, E. W. (1993). Newcomer information seeking: Exploring types, modes, sources, and out-comes. Academy of Management Journal, 36, 557-589.

Nahapiet, J., \& Ghoshal, S. (1998). Social capital, intellectual capital, and the organizational advantage. The Academy of Management Review, 23(2), 242-266. https://doi.org/10.2307/259373

Nonaka, I. (1994). A dynamic theory of organizational knowledge creation. Organization Science, 5(1), 14-37. https://doi.org/10.1287/orsc.5.1.14

Nonaka I. \& Takeuchi, H. (1995). The knowledge-creating company. New York: Oxford University Press.

Podolny, J. \& Baron, J. (1997). Resources and relationships: social networks and mobility in the workplace. American Sociological Review, 62, 673-693. https://doi.org/10.2307/2657354

Porter, C. M. \& Woo, S. E. (2015). Untangling the networking phenomenon: A dynamic psychological perspective on how and why people network. Journal of Management, 11, 1 24. https://doi.org/10.1177/0149206315582247

Powell, W.W., \& Snellman, K. (2004). The knowledge economy. Annual Review of Sociology, 30, 199-220. https://doi.org/10.1146/annurev.soc.29.010202.100037

Putnam, R.D. (1995). Bowling alone: America's declining social capital, Journal of Democracy, 6(1), 65-78. https://doi.org/10.1353/iod.1995.0002 
Reagans, R., \& McEvily, B. (2003). Network structure and knowledge transfer: The effects of cohesion and range. Administrative Science Quarterly, 48(2): 240-267. https://doi.org/10.2307/3556658

Shah, P. (1998). Who are employees' social referents? Using a network perspective to determine referent others. Academy of Management Journal, 41(3), 249-268. https://doi.org/10.2307/256906

Seibert, S. E., Kraimer, M. L., \& Liden, R. C. (2001). A social capital theory of career success. Academy of Management Journal, 44, 219-237. https://doi.org/10.2307/3069452

Sparrowe, R., Liden, R., Wayne, S., \& Kraimer, M. (2001). Social networks and the performance of individuals and groups. Academy of Management Journal, 44(2), 216-325.

Spender, J. C. (1996). Making knowledge the basis of a dynamic theory of the firm. Strategic Management Journal, 17, 45-62. https://doi.org/10.1002/smj.4250171106

Tangaraja, G., Mohd Rasdi, R., Ismail, M., \& Samah, B. A. (2015). Fostering knowledge sharing behavior among public sector managers: a proposed model for the Malaysian public service. Journal of Knowledge Management, 19(1), 121-140.

Tsai , W. \& Ghoshal, S. (1998). Social capital and value creation: The role of intrafirm networks. The Academy of Management Journal, 41(4), 464-476.

Uslaner, E.M. (2000). Social capital and the net. Communications of the ACM, 43(12), 60-65.

Wang, S., \& Noe, R.A. (2010). Knowledge sharing: A review and directions for future research. Human Resource Management Review, 20, 115-131.

Wang, S., Noe, R.A., Wang, Z.M. (2014) Motivating knowledge sharing in knowledge management systems: A quasi-field experiment, Journal of Management, 40, 978-1009

Wasko, M. M., \& Faraj, S. (2005). Why should I share? Examining social capital and knowledge contribution in electronic networks of practice. MIS Quarterly, 29(1), 35-57.

Wasserman, S., \& Faust, K. (1994). Social network analysis: Methods and application. New York: Cambridge University Press. https://doi.org/10.1017/CBO9780511815478

Wellman, B., Quan-Haase,A, \& Witte, K.N. Hampton.(2001). Does the Internet increase, decrease, or supplement social capital? Social networks, participation, and community commitment, American Behavioral Scientist, 45(3), 437-456.

Wellman, B. \& Wortley, S. (1990). Different strokes from different folks: Community ties and social support. American Journal of Sociology, 96(3), 558-588. https://doi.org/10.1086/229572

Yao, L. J., Kam, T. H. Y., \& Chan, S. H. (2007). Knowledge sharing in Asian public administration sector: The case of Hong Kong. Journal of Enterprise Information Management, 20(1), 51-69. https://doi.org/10.1108/17410390710717138

Yli-Renko, H., Autio, E., \& Sapienza, H.J. (2001). Social capital, knowledge acquisition, and knowledge exploitation in young technology-based firms. Strategic Management Journal. 22(6), 587-613. https://doi.org/10.1002/smj.183

Zagenczyk, T. \& Murrell, A. (2009). It is better to receive than to give: Advice network effects on job and work-unit attachment. Journal of Business and Psychology, 24, 139-152. https://doi.org/10.1007/s10869-009-9095-3 